\title{
Status and determinants of intra-household food allocation in rural Nepal
}

\author{
Helen A. Harris-Fry $\mathbb{1}^{1,2} \cdot$ Puskar Paudel $^{3} \cdot$ Niva Shrestha $^{1,2} \cdot$ Tom Harrisson $^{2} \cdot$ B. James Beard ${ }^{1,2} \cdot$ Sonali Jha $^{3}$. \\ Bhim P. Shrestha ${ }^{3} \cdot$ Dharma S. Manandhar $^{3} \cdot$ Anthony M.D.L. Costello ${ }^{2,4} \cdot$ Mario Cortina-Borja $^{5} \cdot$ Naomi M. Saville $^{2}$
}

Received: 1 September 2017 / Revised: 13 November 2017 / Accepted: 22 November 2017 / Published online: 22 January 2018

(c) The Author(s) 2018. This article is published with open access

\begin{abstract}
Background/objectives Understanding of the patterns and predictors of intra-household food allocation could enable nutrition programmes to better target nutritionally vulnerable individuals. This study aims to characterise the status and determinants of intra-household food and nutrient allocation in Nepal.

Subjects/methods Pregnant women, their mothers-in-law and male household heads from Dhanusha and Mahottari districts in Nepal responded to 24-h dietary recalls, thrice repeated on non-consecutive days ( $n=150$ households; 1278 individual recalls). Intra-household inequity was measured using ratios between household members in food intakes (food shares); food-energy intake proportions ('food shares-to-energy shares', FS:ES); calorie-requirement proportions ('relative dietary energy adequacy ratios', RDEARs) and mean probability of adequacy for 11 micronutrients (MPA ratios). Hypothesised determinants were collected during the recalls, and their associations with the outcomes were tested using multivariable mixed-effects linear regression models.

Results Women's diets (pregnant women and mothers-in-law) consisted of larger FS:ES of starchy foods, pulses, fruits and vegetables than male household heads, whereas men had larger FS:ES of animal-source foods. Pregnant women had the lowest MPA (37\%) followed by their mothers-in-law (52\%), and male household heads (57\%). RDEARs between pregnant women and household heads were $31 \%$ higher (log-RDEAR coeff $=0.27$ (95\% CI 0.12, 0.42), $P<0.001)$ when pregnant women earned more or the same as their spouse, and log-MPA ratios between pregnant women and mothers-in-law were positively associated with household-level calorie intakes (coeff $=0.43(0.23,0.63), P<0.001$, per $1000 \mathrm{kcal})$.

Conclusions Pregnant women receive inequitably lower shares of food and nutrients, but this could be improved by increasing pregnant women's cash earnings and household food security.
\end{abstract}

\section{Background}

Pregnant women in South Asia have inadequate intakes of many micronutrients $[1,2]$, and this can translate into

Helen A. Harris-Fry

helen.harris-fry@1shtm.ac.uk

1 London School of Hygiene and Tropical Medicine, London, UK

2 Institute for Global Health, University College London, London, UK

3 Mother and Infant Research Activities, Kathmandu, Nepal

4 Maternal Child and Adolescent Health, World Health Organization, Geneva, Switzerland

5 Great Ormond Street Institute of Child Health, University College London, London, UK comorbidities of multiple micronutrient deficiencies [3]. Inadequate diets during pregnancy are particularly problematic because inadequate weight gain and micronutrient intakes are associated with higher risk of adverse health outcomes, including low birth weight [4] and maternal mortality [5]. In 2013, over half of the world's maternal deaths caused by severe anaemia occurred in South Asia [5].

In South Asia, nutritional inadequacy may be caused by gender-based inequities. At the macro level, the Gender Inequality Index displaces gross domestic product as a predictor of low birthweight, suggesting that inequality is a more important determinant of nutrition than poverty [6]. At the micro level, women [7, 8], particularly pregnant women [9], are discriminated against the allocation of food within households - a trend that is more prominent in South Asia than elsewhere [9]. This may be explained by food 
insecurity [10] or sociocultural factors [7]. For example, women often eat last and least [11], fast more than men [12] and have limited decision-making power over foodpurchasing decisions [13]. Additionally, during pregnancy, women have higher nutritional requirements but often have other pregnancy-specific food restrictions [7].

To improve nutrition during pregnancy, many interventions have aimed to increase household-level food availability, by providing supplements, social transfers [14] or promoting home food production through gardening or livestock programmes [15]. However, if pregnant women are discriminated against, interventions may fail to benefit them.

Recent, high-quality studies on intra-household food allocation are limited [9], and none of them have used probability methods to estimate nutritional adequacy or examined inequities between pregnant women and mothersin-law [16]. The present study from Nepal will describe intra-household allocation of food-related behaviours, food groups and dietary adequacy between pregnant women, mothers-in-law and male household heads, and use a recent theoretical framework [16] to identify determinants of intrahousehold food allocation.

\section{Subjects and methods}

\section{Study population}

The study was conducted in Dhanusha and Mahottari districts, located in Province 2, in the Terai (lowland) region of Nepal. Dhanusha and Mahottari districts have a combined population of $\sim 1.4$ million, and the main source of livelihood is agricultural production [17]. Located in the IndoGangetic floodplains, land is fertile and there are favourable climatic conditions for agricultural production; yet, the prevalence of undernutrition is the highest in the country; $29 \%$ of women in Province 2 are underweight $(<18.5 \mathrm{~kg} /$ $\mathrm{m}^{2}$ ), compared with the national average of $17 \%$ [18].

The pre-specified sampling frame included all maleheaded households, with a pregnant woman in their third trimester who was living with their mother-in-law and enroled in a cluster-randomised controlled trial: the Low Birth Weight South Asia Trial (LBWSAT; http://www. controlled-trials.com/ISRCTN75964374) [19, 20] between June and September 2015. We sampled joint, male-headed households to reduce heterogeneity and because qualitative research indicated that they would be least likely to change food allocation behaviours [13]. Within households, respondents were pregnant women, their mothers-in-law and the male household heads. Dietary data were collected from 805 households in all trial arms, based on a target sample size of 200 households from 19 clusters per arm, to detect a difference of 0.1 'Relative Dietary Energy Adequacy Ratios' (RDEARs) between two trial arms with $80 \%$ power and $95 \%$ confidence. This study uses data from the control arm $(n=150)$ in 20 Village Development Committee areas.

Informed consent was obtained from all respondents and research ethics approval was obtained from the Nepal Health Research Council (108/2012) and University College London Ethical Review Committee (4198/001).

\section{Data collection}

Interviewers collected 24-h dietary recalls using a smartphone tool, described elsewhere [21]. In brief, interviewers conducted dietary recalls, repeated three times per person on non-consecutive days, following five passes each time: collect a free recall using non-specific probes, ask the time and place that each item was consumed, read a list of commonly forgotten foods, recap in chronological order, and collect details on specific food types and portion sizes $[22,23]$.

Food types were selected from a precoded list of foods, including locally available supplements, or typed manually if missing from the list. Portion sizes were estimated using a photographic atlas that was validated for this study and contained 224 graduated discrete, life-sized portion images for 72 foods. We used the same images for similar foods [24]. Data were collected on Android smartphones using CommCare (Version 2.22.0, http://www.commcarehq.org/ home/), an open-source, cloud-based data collection platform. Codes for food items and portions were encoded in quick response (QR) codes and entered into the form using a barcode scanning application ('ZXing Barcode Scanner'). To minimise non-response, pregnant women could respond on behalf of others if they felt confident answering comprehensively. This was not permitted during the first visit when anthropometric measurements were taken. The nutritional composition of raw foods was calculated using a Food Composition Table (FCT) compiled from multiple sources [25-28]. For mixed dishes, we calculated the average nutritional composition from 174 recipes collected prior to dietary data collection.

Body weight and mid-upper arm circumference (MUAC) were measured using Tanita solar-weighing scales and Seca 212 circumference tapes, respectively. Self-reported activity levels, illness, feasting and fasting, food security (months of adequate household food provisioning, MAHFP [29] and household food insecurity access scale, HFIAS [30]) and other diet-related questions were collected, plus the following hypothesised determinants: pregnant women earning the same or more cash than their spouses; gravidity (a proxy for seniority); self-reported empowerment level of pregnant woman (scale 0-10); asset score calculated using principal 
component analysis; household calorie consumption (averaged of the three members, per $1000 \mathrm{kcal}$ ); pregnant woman's husband living overseas; caste or religious group; and season (pre-monsoon or during monsoon). We used other socioeconomic data collected by the main trial surveillance questionnaires [20].

\section{Data analysis}

Foods were aggregated into the ten food groups in the minimum dietary diversity score for women (MDD-W) [31]: (1) grains, white roots and tubers, (2) pulses (beans, peas and lentils), (3) nuts and seeds, (4) dairy, (5) meat, poultry and fish, (6) eggs, (7) dark green leafy vegetables, (8) other vitamin A-rich fruits and vegetables, (9) other vegetables and (10) other fruits. We calculated MDD-W by summing the groups consumed on the first recall (to use the same reference period for which the score was validated), and calculated the proportion consuming an 'adequate' diet ( $\geq 5$ food groups) [31].

Nutritional intakes were estimated by calculating the nutrients from each portion of each food using the FCT, and summing the nutrients from each portion to give total daily intakes. We did not apply nutrient retention factors because of the lack of locally appropriate estimates. Intakes were averaged across the three recall visits.

Dietary adequacy was calculated using the USA Institute of Medicine (IOM) probability approach [32, 33]. First, to achieve normality, nutrient intakes were transformed using a Box-Cox model [34]. Then, using transformed values, we calculated 'usual' intakes from the best linear unbiased predictors resulting from mixed-effects models, fitted separately for each household member type. We treated clusters and individuals as random effects and strata as fixed effects. For all nutrients (except iron for non-pregnant respondents), the probability of adequacy (PA) was calculated by comparing each back-transformed usual intake to the population distribution of requirements, which are normal distributions with means (i.e. estimated average requirements, EARs) and standard deviations. We used WHO/FAO's values for nutritional requirements of vitamin $\mathrm{C}$, thiamin, riboflavin, niacin, vitamin $\mathrm{B}_{6}$, folate, vitamin $B_{12}$ [35], Institute of Medicine's values for calcium [36] and iron [37] and International Zinc Nutrition Consultative Group (IZiNCG)'s recommendations for zinc [38]. Iron requirements for non-pregnant women and men are not normally distributed, so, we calculated PAs using a table of probabilities for different intake intervals, adapted from IOM [37] to assume 5\% bioavailability. The mean probability of adequacy (MPA) was the average PA of all 11 nutrients.

To measure intra-household food allocation, we calculated food shares (FS), food-share-to-energy shares (FS:ES),
RDEARs and MPA ratios. FS are ratios of food group intakes $(\mathrm{g})$ between pairs of individuals for households who consumed any [39]. FS:ES account for different energy intakes between individuals [39], calculated as $\left(\right.$ food intake $\left.\mathrm{a} / \mathrm{kcal} \mathrm{intake}_{\mathrm{a}}\right) /\left(\right.$ food intake $\left.\mathrm{b} / \mathrm{kcal} \mathrm{intake}_{\mathrm{b}}\right)$, for persons a and b. Energy allocation was calculated as the 'Relative Dietary Energy Adequacy Ratio', RDEAR = $\left(\right.$ intakes $_{a} /$ EAR $\left._{a}\right) /\left(\right.$ intakes $_{b} /$ EAR $\left._{b}\right)$ [9]. Energy EARs were calculated according to age, gender, pregnancy status, body weight $(\mathrm{kg})$ and self-reported activity levels, using values by Indian Council of Medical Research [40]. The additional cost of pregnancy was taken to be $390 \mathrm{kcal} / \mathrm{d}$ [40]. MPA ratios were calculated as $\mathrm{MPA}_{\mathrm{a}} / \mathrm{MPA}_{\mathrm{b}}$.

To test for inequity, we adjusted for deviations from normality by log-transforming the ratios and used a random effects linear regression model, treating clusters as a random effect, to test whether the intercept was significantly different from zero.

To identify determinants of food allocation, using RDEARs and MPA ratios as outcomes, we fitted multivariable mixed-effects linear regression models, including all hypothesised determinants. We tested for nonlinear effects of wealth on log-RDEAR and log-MPA ratios [16]. To assess collinearity among predictors, we calculated variance inflation factors (VIFs) [41]. We included all outliers in kcal intakes, and respondents who were fasting or feasting because the results were comparable with analyses excluding outliers, but excluded extreme outliers $(<-8)$ in log-transformed MPA ratios to give normally distributed residuals. Significance levels were set at $P<0.05$.

\section{Code availability}

All analyses were conducted using Stata SE 14 (College Station, TX: StataCorp LP) and Stata code is available upon request with the corresponding author.

\section{Results}

We sampled $75 \%(150 / 199)$ of eligible households. The reasons for non-response included non-consent $(n=5)$ or non-availability $(n=41)$. Some households on the sample list were not sampled because they had become ineligible before the interview, because women had given birth $(n=$ 108) or were temporarily not living with their mothers-inlaw $(n=101)$. The study period also covered pre-monsoon (hottest) and monsoon, mango season and Ramadan. Cluster-adjusted chi-square tests show no significant differences in age, caste, assets, land ownership, education or HFIAS between sampled and non-sampled participants (results not shown). 
Table 1 Household and individual socioeconomic and demographic characteristics, and food-related behaviours

\begin{tabular}{|c|c|c|c|c|c|c|}
\hline $\begin{array}{l}\text { Respondent characteristics } \\
\text { Age, years }\end{array}$ & \multicolumn{2}{|c|}{ Pregnant woman } & \multicolumn{2}{|c|}{ Mother-in-law } & \multicolumn{2}{|c|}{ Household head } \\
\hline Median (25th, 75th centiles) & 21 & $(19,24)$ & 50 & $(44,56)$ & 39 & $(25,56)$ \\
\hline \multicolumn{7}{|l|}{ Age at marriage, years } \\
\hline Mean (SD) & 16.4 & $(1.8)$ & NA & & NA & \\
\hline \multicolumn{7}{|l|}{ Number of previous pregnancies, $\%$} \\
\hline 0 & 32.4 & & NA & & NA & \\
\hline$\geq 1$ & 67.6 & & NA & & NA & \\
\hline \multicolumn{7}{|l|}{ Gestational age, weeks } \\
\hline Median (25th, 75th centiles) & 37 & $(35,38)$ & NA & & NA & \\
\hline \multicolumn{7}{|l|}{ Mid-upper arm circumference, MUAC } \\
\hline Low MUAC, $<23 \mathrm{~cm}, \%$ & 40.0 & & 35.3 & & 14.0 & \\
\hline Mean (SD) & 23.5 & $(2.1)$ & 24.3 & $(3.3)$ & 25.9 & $(2.9)$ \\
\hline \multicolumn{7}{|l|}{ Illness and fasting, $\%$} \\
\hline Any illness in the three dietary recall reference periods & 13.3 & & 12.0 & & 6.7 & \\
\hline Any fasting in the three dietary recall reference periods & 10.0 & & 13.3 & & 8.7 & \\
\hline $\begin{array}{l}\text { Ate more during pregnancy, compared to when not } \\
\text { pregnant }\end{array}$ & 15.1 & & NA & & NA & \\
\hline $\begin{array}{l}\text { Ate the same during pregnancy, compared to when not } \\
\text { pregnant }\end{array}$ & 32.5 & & NA & & NA & \\
\hline $\begin{array}{l}\text { Ate less during pregnancy, compared to when not } \\
\text { pregnant }\end{array}$ & 52.4 & & NA & & NA & \\
\hline \multicolumn{7}{|l|}{ Involvement in food production and preparation, $\%$} \\
\hline Main cook in the household & 77.8 & & 3.2 & & 0 & \\
\hline Involved in decisions about purchasing food & 16.0 & & 50.7 & & 50.0 & \\
\hline Goes outside to do the shopping & 13.4 & & 38.8 & & 57.5 & \\
\hline \multicolumn{7}{|l|}{ Education level, \% } \\
\hline Never went to school & 56.1 & & NA & & NA & \\
\hline Primary to lower secondary & 27.0 & & NA & & NA & \\
\hline Secondary and above & 16.9 & & NA & & NA & \\
\hline \multicolumn{7}{|l|}{ Household-level characteristics } \\
\hline \multicolumn{7}{|l|}{ Caste group, $\%$} \\
\hline Dalit/Muslim (most disadvantaged groups) & 36.2 & & & & & \\
\hline Janajati/other Terai castes & 42.9 & & & & & \\
\hline Yadav/Brahmin (least disadvantaged) & 20.9 & & & & & \\
\hline \multicolumn{7}{|l|}{ Land ownership, \% } \\
\hline Owns no land & 30.9 & & & & & \\
\hline \multicolumn{7}{|l|}{ Household food security, $\%$} \\
\hline $\begin{array}{l}\text { Households with enough food to meet household needs in } \\
\text { the year prior to interview (MAHFP) }\end{array}$ & 91.0 & & & & & \\
\hline $\begin{array}{l}\text { Households experiencing no food insecurity over the past } \\
4 \text { weeks prior to interview (HFIAS) }\end{array}$ & 69.4 & & & & & \\
\hline
\end{tabular}

$n=150$; response rates for these variables ranged from $89 \%$ (food security) to $100 \%$ (age, caste)

$N A$ not available or applicable, HFIAS household food insecurity access scale, MAHFP months of adequate household food provisioning

Respondent characteristics are summarised in Table 1. Almost a third were landless, over a third were from disadvantaged groups (Dalit or Muslim) and over half of pregnant women had not attended school. There was some food insecurity in the month preceding the interview in $30 \%$ of households, though only $9 \%$ cited any months 


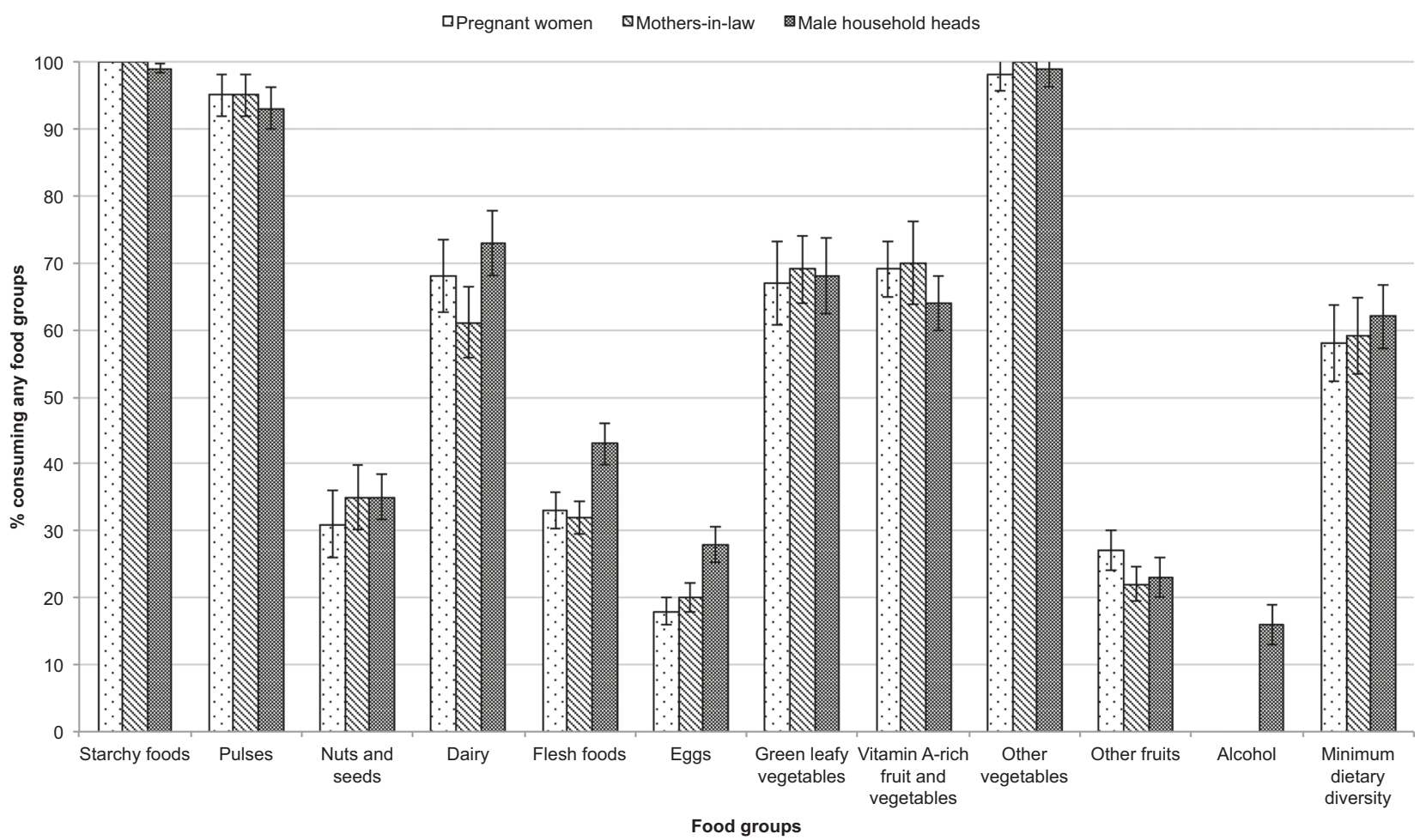

Fig. 1 Percentage of pregnant women, mothers-in-law and male household heads consuming any of each food group, based on 3 days of dietary recall, and consuming minimum dietary diversity based on 1 day of dietary recall

of inadequate household food provisioning in the preceding year. Male household heads had the lowest incidences of illness and fasting, and prevalence of low MUAC (14\% $<23 \mathrm{~cm}$ [42]) compared with pregnant women (40\%) or mothers-in-law (35\%). Men and mothers-in-law were involved in food shopping and decisionmaking, whereas most pregnant women did the cooking $(78 \%)$.

For all household members, almost all (98\%) respondents ate rice, around three quarters ate dal (spiced lentil soup) and $65 \%$ ate roti (flatbread). Other food items, that $>20 \%$ of respondents consumed at least some of, were tea with sugar and milk, mango, pointed gourd curry, fried spicy potato (bhujiya) and buffalo milk. Only $9 \%$ of pregnant women and $32 \%$ of mothers-in-law consumed food outside of the home over the 3-day recall, compared with $73 \%$ of male household heads. Household heads commonly ate outdoors or in a teashop, and ate plain, puffed or beaten rice (18\%), vegetable curry (13\%), tea with sugar and milk (9\%), flatbreads (9\%), deep-fried sweet or savoury snacks like samosa, litti and jeri (9\%), dal (6\%) and alcohol (6\%). All household members consumed around two-thirds of their calories before 11 a.m. or after 7 p.m.

\section{Intra-household differences in food consumption and nutrient adequacy}

The percentage of pregnant women, mothers-in-law and male household heads consuming any of the 10 food groups or alcohol, and the percentage consuming an adequate diet ( $\geq 5$ food groups), is given in Fig. 1. Error bars show standard errors of the mean, adjusted for clustering. Mean intakes of those who consumed any of each group are given in Table 2. More household heads consumed animal-source foods (flesh foods like meat or fish, eggs and dairy) than pregnant women or mothers-in-law. A total of $43 \%$ of household heads consumed flesh foods compared with a third of pregnant women or mothers-in-law; $73 \%$ of household heads consumed dairy compared with $61 \%$ of mothers-in-law. More pregnant women ate green leafy vegetables or fruits than mothers-in-law or household heads. Consumption of most other foods-especially common foods like starchy foods, pulses and vegetables-and mean dietary diversity score (between 4.6 and 4.9) was similar for all three household members.

Table 3 reports the tests for equality in log-FS and logFS:ES. Women (pregnant women and mothers-in-law) had lower dietary diversity and intakes of starchy foods, pulses, vegetables and animal-source foods than male household 
Table 2 Mean consumption of food groups for household members who consumed any, and mean dietary diversity score, for each household member

\begin{tabular}{|c|c|c|c|c|c|c|c|c|c|c|c|c|}
\hline \multirow[b]{3}{*}{ Food group ${ }^{a}$} & \multicolumn{4}{|c|}{ Pregnant women } & \multicolumn{4}{|c|}{ Mothers-in-law } & \multicolumn{4}{|c|}{ Household head } \\
\hline & \multicolumn{2}{|c|}{$\begin{array}{l}\text { Ate any of the } \\
\text { food group }\end{array}$} & \multicolumn{2}{|c|}{$\begin{array}{l}\text { Intake, } g, \text { if any } \\
\text { consumed }\end{array}$} & \multicolumn{2}{|c|}{$\begin{array}{l}\text { Ate any of the } \\
\text { food group }\end{array}$} & \multicolumn{2}{|c|}{$\begin{array}{l}\text { Intake, } g \text {, if any } \\
\text { consumed }\end{array}$} & \multicolumn{2}{|c|}{$\begin{array}{l}\text { Ate any of } \\
\text { the food } \\
\text { group }\end{array}$} & \multicolumn{2}{|c|}{$\begin{array}{l}\text { Intake, } g \text {, if any } \\
\text { consumed }\end{array}$} \\
\hline & $n$ & $(\%)$ & Mean & $(\mathrm{SD})$ & $n$ & $(\%)$ & Mean & $(\mathrm{SD})$ & $n$ & $(\%)$ & Mean & (SD) \\
\hline Starchy staples & 150 & $(100)$ & 896 & (319) & 150 & $(100)$ & 886 & $(367)$ & 149 & 99 & 1098 & $(427)$ \\
\hline $\begin{array}{l}\text { Pulses (beans, peas and } \\
\text { lentils) }\end{array}$ & 143 & (95) & 96 & (57) & 142 & (95) & 96 & $(56)$ & 140 & 93 & 113 & $(69)$ \\
\hline Nuts and seeds & 47 & (31) & 6.3 & (21) & 52 & (35) & 6.7 & (13) & 53 & 35 & 6.6 & (20) \\
\hline Dairy & 102 & $(68)$ & 257 & $(224)$ & 91 & $(61)$ & 240 & (197) & 109 & 73 & 324 & (272) \\
\hline $\begin{array}{l}\text { Flesh foods (meat, fish } \\
\text { and shellfish) }\end{array}$ & 49 & (33) & 52 & (53) & 48 & (32) & 57 & (43) & 65 & 43 & 73 & $(61)$ \\
\hline Eggs & 27 & (18) & 4.8 & (12) & 30 & (20) & 7.9 & (26) & 42 & 28 & 7.1 & (20) \\
\hline Green leafy vegetables & 100 & $(67)$ & 25 & $(31)$ & 103 & (69) & 24 & (29) & 102 & 68 & 22 & (24) \\
\hline $\begin{array}{l}\text { Other vitamin A-rich } \\
\text { fruits and vegetables }\end{array}$ & 103 & $(69)$ & 201 & $(239)$ & 105 & $(70)$ & 226 & $(282)$ & 96 & 64 & 214 & $(239)$ \\
\hline Other vegetables & 147 & $(98)$ & 158 & $(103)$ & 150 & $(100)$ & 154 & $(95)$ & 148 & 99 & 189 & (122) \\
\hline Other fruits & 40 & $(27)$ & 52 & $(47)$ & 33 & $(22)$ & 55 & $(65)$ & 35 & 23 & 32 & $(28)$ \\
\hline Alcohol & 0 & $(0)$ & 0 & $(0)$ & 0 & $(0)$ & 0 & $(0)$ & 24 & 16 & 45 & $(111)$ \\
\hline $\begin{array}{l}\%(n) \text { consuming } \geq 5 \\
\text { groups; mean dietary } \\
\text { diversity }{ }^{\mathrm{b}}\end{array}$ & 87 & $(58)$ & 4.6 & $(1.2)$ & 88 & $(59)$ & 4.7 & $(1.3)$ & 93 & 62 & 4.9 & $(1.3)$ \\
\hline
\end{tabular}

${ }^{a}$ Intakes based on average over 3-day recall period

${ }^{\mathrm{b}}$ Dietary diversity score based on 1-day recall period

heads. Comparing log-FS:ES, a larger share of women's than men's diets was provided by starchy foods, pulses, vitamin A-rich fruits and vegetables, and green leafy vegetables. Pregnant women had 34\% higher shares of green leafy vegetables. Men's diets comprised $18 \%$ larger shares of flesh foods than pregnant women and 24\% larger shares of dairy than the mothers-in-law. Log-FS and log-FS: ES were not different between pregnant women and mothers-in-law ( $P>0.4$ for all foods; results not shown).

Intakes, EARs and PAs for each household member are reported in Table 4. Pregnant women had the lowest MPA (37\%) compared with mothers-in-law (52\%) and male household heads $(57 \%)$. Vitamin $\mathrm{B}_{12}$ intakes were inadequate for almost all respondents.

\section{Testing for equity and the determinants of equity}

Table 5 reports calorie (log-transformed log-RDEARs) and micronutrient (log-transformed MPA ratios) allocations, and determinants of these outcomes. We focus on allocation between pregnant women and other household members because of the nutritional importance of diet during pregnancy.

Between pregnant women and household heads, RDEARs were 18\% lower, and MPA ratios 38\% lower, than perfectly equitable households. Between pregnant women and mothers-in-law, RDEARs were $14 \%$ lower, and MPA $42 \%$ lower, than perfect equity. In $17 \%$ of households, pregnant women consumed $<90 \%$ of EARs, while the household heads consumed $>110 \%$ of EARs. In $11 \%$ of households, pregnant women consumed $<90 \%$ of EARs, while mothers-in-law consumed $>110 \%$ of EARs.

RDEARs were positively associated with women earning the same or more than their spouse, and the pregnant woman's husband living overseas. Household-level intakes were associated with MPA ratios. There was no evidence of a nonlinear relationship between wealth and calorie or micronutrient allocation, as there was no association with a quadratic term or when testing different quintiles.

\section{Discussion}

Foods and nutrients are allocated inequitably within households, with clear male advantage. Male household heads consume more animal-source foods, eat special foods like deep-fried snacks and alcohol outside of the home, and have the highest dietary adequacy, whereas women eat more low-status foods and have lower dietary adequacy, particularly pregnant women due to their elevated 
Table 3 Differences in food shares (FS) and food-shares-to-energy shares (FS:ES) for each food group, between different pairs of household members who ate any of each food group

\begin{tabular}{|c|c|c|c|c|c|c|c|}
\hline \multirow[b]{2}{*}{ Food group $^{a}$} & \multicolumn{3}{|c|}{ Log FS } & \multicolumn{3}{|c|}{ Log FS:ES } & \multirow[b]{2}{*}{$P$} \\
\hline & $n$ & Mean & $95 \% \mathrm{CI}$ & $P$ & Mean & $95 \% \mathrm{CI}$ & \\
\hline \multicolumn{8}{|l|}{ Pregnant woman : household head } \\
\hline Starchy staples & 149 & -0.21 & $(-0.28,-0.13)$ & $<0.001$ & 0.05 & $(-0.00,0.10)$ & 0.068 \\
\hline Pulses (beans, peas and lentils) & 137 & -0.11 & $(-0.22,-0.00)$ & 0.047 & 0.14 & $(0.03,0.26)$ & 0.017 \\
\hline Nuts and seeds & 35 & -0.05 & $(-0.33,0.22)$ & 0.70 & 0.14 & $(-0.11,0.39)$ & 0.271 \\
\hline Dairy & 88 & -0.31 & $(-0.53,-0.10)$ & 0.004 & -0.07 & $(-0.30,0.17)$ & 0.578 \\
\hline Flesh foods (meat, fish and shellfish) & 43 & -0.44 & $(-0.62,-0.26)$ & $<0.001$ & -0.20 & $(-0.37,-0.04)$ & 0.015 \\
\hline Eggs & 24 & -0.47 & $(-0.81,-0.12)$ & 0.007 & -0.28 & $(-0.63,0.07)$ & 0.115 \\
\hline Green leafy vegetables & 94 & 0.00 & $(-0.16,0.25)$ & 0.69 & 0.29 & $(0.06,0.52)$ & 0.012 \\
\hline Other vitamin A-rich fruits and vegetables & 79 & 0.23 & $(-0.13,0.59)$ & 0.20 & 0.47 & $(0.10,0.83)$ & 0.012 \\
\hline Other vegetables & 146 & -0.22 & $(-0.31,-0.14)$ & $<0.001$ & 0.00 & $(-0.06,0.11)$ & 0.593 \\
\hline Other fruits & 21 & 0.53 & $(-0.68,1.73)$ & 0.39 & 0.74 & $(-0.42,1.90)$ & 0.213 \\
\hline Dietary diversity ${ }^{\mathrm{b}}$ & 149 & -0.07 & $(-0.11,-0.03)$ & 0.001 & -0.06 & $(-0.11,-0.01)$ & 0.022 \\
\hline \multicolumn{8}{|l|}{ Mother-in-law : household head } \\
\hline Starchy staples & 149 & -0.23 & $(-0.33,-0.13)$ & $<0.001$ & 0.00 & $(-0.00,0.08)$ & 0.07 \\
\hline Pulses (beans, peas and lentils) & 136 & -0.15 & $(-0.30,-0.01)$ & 0.035 & 0.12 & $(0.02,0.22)$ & 0.017 \\
\hline Nuts and seeds & 39 & -0.28 & $(-0.62,0.06)$ & 0.107 & 0.00 & $(-0.36,0.30)$ & 0.84 \\
\hline Dairy & 81 & -0.47 & $(-0.67,-0.27)$ & $<0.001$ & -0.28 & $(-0.47,-0.08)$ & 0.005 \\
\hline Flesh foods (meat, fish and shellfish) & 40 & -0.38 & $(-0.65,-0.10)$ & 0.008 & -0.13 & $(-0.37,0.10)$ & 0.27 \\
\hline Eggs & 27 & -0.34 & $(-0.63,-0.06)$ & 0.019 & -0.12 & $(-0.42,0.19)$ & 0.45 \\
\hline Green leafy vegetables & 95 & 0.00 & $(-0.20,0.24)$ & 0.862 & 0.29 & $(0.07,0.52)$ & 0.011 \\
\hline Other vitamin A-rich fruits and vegetables & 83 & 0.32 & $(-0.18,0.82)$ & 0.213 & 0.55 & $(0.09,1.02)$ & 0.020 \\
\hline Other vegetables & 148 & -0.24 & $(-0.33,-0.14)$ & $<0.001$ & 0.00 & $(-0.06,0.12)$ & 0.56 \\
\hline Other fruits & 17 & 0.32 & $(-0.96,1.60)$ & 0.623 & 0.57 & $(-0.77,1.91)$ & 0.41 \\
\hline Dietary diversity ${ }^{\mathrm{b}}$ & 149 & -0.07 & $(-0.13,-0.01)$ & 0.013 & -0.02 & $(-0.09,0.05)$ & 0.54 \\
\hline
\end{tabular}

${ }^{a}$ Intakes based on average over 3-day recall period; kcal intakes adjusted for by calculating food share to energy share [FS:ES between persons a and $\mathrm{b}=\left(\right.$ intake $\left._{\mathrm{a}} / \mathrm{kcal}_{\mathrm{a}}\right) /\left(\right.$ intake $\left._{\mathrm{b}} / \mathrm{kcal}_{\mathrm{b}}\right)$ ]

${ }^{\mathrm{b}}$ Dietary diversity score is based on 1-day recall period, and 'log-FS' was the log-transformed ratio between dietary diversity scores, whereas 'logFS:ES' used the same log-dietary diversity ratio but adjusted for the corresponding log-transformed kcal intake ratios.

requirements. The intra-household gradient in dietary adequacy (men>mothers-in-law $>$ pregnant women) mirrors the gradient in MUAC and is determined by within-household disparities in earned cash income, pregnant woman's husband working overseas, and household-level calorie consumption.

The gender division in food allocation is consistent with other studies from Nepal. One study found that men were preferentially allocated 'luxury' foods such as tea and deepfried snacks [43], and another found that men had higher micronutrient adequacy than women [11]. We found no clear disparity in food allocation between pregnant women and their mothers-in-law, which is surprising given the well-reported social hierarchy between women in South Asia [44]. However, pregnant women's intakes were less adequate because their elevated requirements were not compensated for, perhaps due to male favouritism, fear of giving birth to a large baby, fasting for a boy child [13], food proscriptions [7] or feeling full since women were in their third trimester [45].

We found higher nutrient intakes than studies from urban Nepal [2] and rural Bangladesh [1]. This may be because rural populations eat more, because they engage in physically strenuous agricultural labour, whereas urban populations may be more sedentary. We did not measure the physical activity levels of respondents, beyond a basic selfassessment of activity levels, nor did these other studies, so, we cannot determine whether differences in workloads could explain these differences in dietary intakes. Future work could examine urban-rural differences, and improve the accuracy of these dietary adequacy estimates (particularly calorie adequacy ratios and RDEARs), by incorporating the use of accelerometers to quantify energy balance. During data collection, we also noticed some very high intakes, which interviewers explained were due to Muslims feasting after sunset. Only 13\% of our sample was Muslim, 
Table 4 Daily estimated average requirements, nutrient intakes and probability of adequacy by household member

\begin{tabular}{|c|c|c|c|c|c|c|c|c|}
\hline \multirow[b]{3}{*}{ Nutrient } & \multicolumn{8}{|c|}{ Pregnant women } \\
\hline & \multicolumn{2}{|c|}{ Requirements $^{\mathrm{a}}$} & \multicolumn{3}{|c|}{ Intakes $^{\mathrm{b}}$} & \multicolumn{3}{|c|}{ Probability of adequacy, $\%$} \\
\hline & EAR & $(\mathrm{SD})$ & Mean & $(\mathrm{SD})$ & Median & Mean & $(\mathrm{SD})$ & Median \\
\hline \multicolumn{9}{|l|}{ Pregnant women } \\
\hline Energy, kJ/d & - & - & 9372 & $(3056)$ & 8983 & - & - & - \\
\hline Energy, $\mathrm{kcal} / \mathrm{d}$ & - & - & 2239 & $(730)$ & 2146 & - & - & - \\
\hline Protein, g/d & - & - & 68 & (24) & 65 & - & - & - \\
\hline Vitamin $\mathrm{C}, \mathrm{mg} / \mathrm{d}$ & 40 & $(4.0)$ & 133 & $(144)$ & 96 & 91 & (24) & 100 \\
\hline Vitamin A, RE & 370 & $(74)$ & 486 & $(449)$ & 359 & 17 & $(25)$ & 7 \\
\hline Thiamin, mg/d & 1.2 & $(0.1)$ & 1.5 & $(0.7)$ & 1.5 & 65 & (39) & 86 \\
\hline Riboflavin, mg/d & 1.2 & $(0.1)$ & 1.1 & $(0.6)$ & 1.0 & 20 & (34) & 0 \\
\hline Niacin, mg/d & 14 & $(2.1)$ & 16 & $(7.1)$ & 15 & 54 & (36) & 53 \\
\hline Vitamin $\mathrm{B}_{6}, \mathrm{mg} / \mathrm{d}$ & 1.6 & $(0.2)$ & 2.2 & $(0.8)$ & 2.1 & 79 & (33) & 99 \\
\hline Folate, $\mu \mathrm{g} / \mathrm{d}$ & 520 & $(52)$ & 639 & $(624)$ & 325 & 24 & $(40)$ & 0 \\
\hline Vitamin $B_{12}, \mu \mathrm{g} / \mathrm{d}$ & 2.2 & $(0.2)$ & 0.8 & $(0.9)$ & 0.4 & 0 & $(0.0)$ & 0 \\
\hline Iron, $\mathrm{mg} / \mathrm{d}^{\mathrm{c}}$ & 22 & $(2.1)$ & 25 & $(25)$ & 17 & 20 & (36) & 0 \\
\hline Zinc, $\mathrm{mg} / \mathrm{d}^{\mathrm{d}}$ & 12 & $(1.5)$ & 11 & $(4.0)$ & 11 & 29 & (33) & 10 \\
\hline Calcium, mg/d & 800 & $(100)$ & 654 & $(462)$ & 505 & 14 & $(31)$ & 0 \\
\hline Mean PA & - & - & - & - & - & 37 & (20) & 36 \\
\hline \multicolumn{9}{|l|}{ Mothers-in-law } \\
\hline Energy, kJ/d & - & - & 9326 & (3324) & 9163 & - & - & - \\
\hline Energy, kcal/d & - & - & 2228 & (794) & 2189 & - & - & - \\
\hline Protein, g/d & - & - & 67 & $(28)$ & 65 & - & - & - \\
\hline Vitamin $\mathrm{C}, \mathrm{mg} / \mathrm{d}$ & 30 & $(3.0)$ & 138 & $(136)$ & 98 & 96 & (17) & 100 \\
\hline Vitamin A, RE & 270 & $(54)$ & 511 & $(646)$ & 333 & 40 & (38) & 29 \\
\hline Thiamin, mg/d & 0.9 & $(0.1)$ & 1.5 & $(0.7)$ & 1.4 & 88 & (28) & 100 \\
\hline Riboflavin, mg/d & 0.9 & $(0.1)$ & 1.0 & $(0.6)$ & 0.9 & 39 & $(41)$ & 17 \\
\hline Niacin, mg/d & 11 & $(1.7)$ & 16 & $(7.2)$ & 16 & 79 & $(32)$ & 99 \\
\hline Vitamin $\mathrm{B}_{6}, \mathrm{mg} / \mathrm{d}$ & 1.1 & $(0.1)$ & 2.2 & $(0.8)$ & 2.1 & 100 & $(0)$ & 100 \\
\hline Folate, $\mu \mathrm{g} / \mathrm{d}$ & 320 & $(32)$ & 350 & $(165)$ & 325 & 34 & (38) & 14 \\
\hline Vitamin $B_{12}, \mu \mathrm{g} / \mathrm{d}$ & 2 & $(0.2)$ & 0.6 & $(2.1)$ & 0.3 & 0 & $(0)$ & 0 \\
\hline Iron, $\mathrm{mg} / \mathrm{d}^{\mathrm{c}}$ & - & - & 15 & (7) & 14 & 2.7 & $(7.6)$ & 0 \\
\hline Zinc, $\mathrm{mg} / \mathrm{d}^{\mathrm{d}}$ & 7 & $(0.9)$ & 11 & (5) & 11 & 87 & (28) & 100 \\
\hline Calcium, mg/d ${ }^{\mathrm{e}}$ & 800 & $(100)$ & 511 & $(277)$ & 434 & 6.2 & $(20)$ & 0 \\
\hline Mean PA & - & - & - & - & - & 52 & (16) & 51 \\
\hline \multicolumn{9}{|c|}{ Male household heads } \\
\hline Energy, kJ/d & - & - & 11,892 & $(3692)$ & 12,085 & - & - & - \\
\hline Energy, kcal/d & - & - & 2841 & $(882)$ & 2887 & - & - & - \\
\hline Protein, g/d & - & - & 87 & (29) & 84 & - & - & - \\
\hline Vitamin $\mathrm{C}, \mathrm{mg} / \mathrm{d}$ & 40 & $(4.0)$ & 128 & $(105)$ & 91 & 90 & $(27)$ & 100 \\
\hline Vitamin A, RE & 300 & $(60)$ & 502 & $(402)$ & 355 & 45 & $(38)$ & 36 \\
\hline Thiamin, mg/d & 1 & $(0.1)$ & 2.0 & $(1.0)$ & 1.9 & 95 & (19) & 100 \\
\hline Riboflavin, mg/d & 1 & $(0.1)$ & 1.3 & $(0.7)$ & 1.2 & 65 & $(40)$ & 88 \\
\hline Niacin, mg/d & 12 & $(1.8)$ & 22 & $(9.8)$ & 21 & 95 & $(17)$ & 100 \\
\hline Vitamin $\mathrm{B}_{6}, \mathrm{mg} / \mathrm{d}$ & 1.1 & $(0.1)$ & 2.8 & $(1.0)$ & 2.7 & 99 & (9) & 100 \\
\hline Folate, $\mu \mathrm{g} / \mathrm{d}$ & 320 & $(32)$ & 402 & $(158)$ & 385 & 60 & $(41)$ & 77 \\
\hline Vitamin $B_{12}, \mu g / d$ & 2 & $(0.2)$ & 0.9 & $(1.2)$ & 0.6 & 2.7 & (15) & 0.0 \\
\hline
\end{tabular}


Table 4 (continued)

\begin{tabular}{|c|c|c|c|c|c|c|c|c|}
\hline \multirow[b]{3}{*}{ Nutrient } & \multicolumn{8}{|c|}{ Pregnant women } \\
\hline & \multicolumn{2}{|c|}{ Requirements $^{\mathrm{a}}$} & \multicolumn{3}{|c|}{ Intakes $^{\mathrm{b}}$} & \multicolumn{3}{|c|}{ Probability of adequacy, $\%$} \\
\hline & EAR & $(\mathrm{SD})$ & Mean & (SD) & Median & Mean & (SD) & Median \\
\hline Iron, $\mathrm{mg} / \mathrm{d}^{\mathrm{c}}$ & - & - & 19 & $(6.7)$ & 19 & 25 & (24) & 20 \\
\hline Zinc, $\mathrm{mg} / \mathrm{d}^{\mathrm{d}}$ & 15 & $(1.9)$ & 14 & $(4.7)$ & 14 & 29 & $(31)$ & 16 \\
\hline Calcium, mg/d & 800 & $(100)$ & 686 & (407) & 597 & 16 & (32) & 0.1 \\
\hline Mean PA & - & - & - & - & - & 57 & (17) & 60 \\
\hline
\end{tabular}

${ }^{a}$ EARs using WHO/FAO values (33), unless otherwise stated

${ }^{\mathrm{b}}$ Intakes reported as mean intakes, averaged across the three dietary recalls

${ }^{\mathrm{c}}$ Institute of Medicine values for iron (35). We assumed low bioavailability of iron (5\%), except for iron in pregnant women who have higher absorption (23\%) during pregnancy. Iron probabilities of adequacy for mothers-in-law and men were calculated using a table of probabilities for different intervals of usual intakes, adapted from IOM but assuming 5\% bioavailability

${ }^{\mathrm{d}}$ Based on International Zinc Nutrition Consultative Group (IZiNCG) recommendations (36). We assumed a low bioavailability of zinc (25\% absorption for women; $18 \%$ for men)

${ }^{\mathrm{e}}$ Institute of Medicine values for calcium (34).

and analyses without fasting and feasting households gave similar results.

Other variance between studies may be explained by temporal and methodological differences, such as different dietary assessment methods. We used a repeated 24-h recall method using a photographic atlas to estimate portion sizes, whereas other studies from Nepal and Bangladesh used weighed food records over a 24-h recall period [2], and/or direct observations $[1,11]$ to measure diets. Ideally, we would have used weighed methods to give a continuous measure of portion sizes (rather than the categorical measure introduced by the atlas), and also used observations rather than recall-based methods to reduce error introduced by respondents' inaccuracies in their conceptualisation and recall of portion sizes [46, 47]. During pilot testing, we found that direct observations were not feasible because they were time consuming and burdensome on respondents. Also, it was culturally inappropriate for male interviewers to spend long periods of time in or near the kitchen with the female cook, making both weighed and observational methods difficult for male interviewers. The few female interviewers we did employ (few local women were sufficiently qualified) were not permitted to spend nights away from home or travel in the dark to conduct direct observations [24]. Nevertheless, our validation study, which found moderate agreement between portion sizes that were weighed and estimated 24-h later using a photographic atlas [24], gives us some confidence in our dietary intake estimates.

Relative cash incomes predicted intra-household calorie allocations, which is consistent with the limited evidence on this association [16], and could be due to perceptions of deservedness [12], a way of rewarding earners [48] or because nutritional investment in economically productive members yields higher incomes [49]. We found an association between household-level calorie consumption and micronutrient allocation but not calorie allocation; other studies have also found no association between food security and calorie allocation [16]. The association between husbands living overseas and food allocation may be explained by women receiving overseas remittances, although a study from the same district found that women worried about the care they would receive from in-laws when their husbands were away [50].

The external validity is limited by our selective sampling of joint, male-headed households, sampling only three respondents within each household, and the 4-month survey period, although we found no effect of season on food allocation. We focused on comparisons between pregnant women and household members who we hypothesised to be favoured in the allocation of foods, and who we hoped would change their behaviours due to our intervention. However, this prevented us from comparing pregnant women with less senior household members (such as children, adolescents or more junior non-pregnant women), who might also be nutritionally vulnerable.

There are a few limitations in the analyses. We are unable to attribute causality to the associations, and are also limited by the sample size. Using data from all study arms could have increased statistical power, but we anticipated interactions between the predictors and study arm. To limit non-response, pregnant woman sometimes answered on behalf of others $34 \%$ and $37 \%$ of household heads, and $17 \%$ and $21 \%$ of mothers-in-law, in the second and third visits, respectively). Therefore, food eaten outside may have been missed. If so, dietary intakes of mothers-in-law and male household heads, as well as allocation ratios, would be underestimated. This was particularly concerning for the 
Table 5 Tests for intra-household equity and the determinants of inequity in the allocation of energy (RDEARs) and nutrients (MPA ratios) using multivariable linear regression

\begin{tabular}{|c|c|c|c|c|c|c|}
\hline & \multicolumn{3}{|c|}{ Pregnant woman : household head } & \multicolumn{3}{|c|}{ Pregnant woman : mother-in-law } \\
\hline & Coeff. & $(95 \% \mathrm{CI})$ & $P$ & Coeff. & $(95 \% \mathrm{CI})$ & $P$ \\
\hline \multicolumn{7}{|l|}{$\log -R D E A R$} \\
\hline Crude mean outcome $(n=149)$ & -0.20 & $(-0.26,0.15)$ & $<0.001$ & -0.15 & $\begin{array}{l}(-0.22 \\
-0.07)\end{array}$ & $<0.001$ \\
\hline$n$ (fitted in multivariable model) & 145 & & & 145 & & \\
\hline \multicolumn{7}{|c|}{ Earning disparities between pregnant women and their spouse } \\
\hline Earns less than the spouse & Ref & & & Ref & & \\
\hline Earns more or same as the spouse & 0.27 & $(0.12,0.42)$ & $<0.001$ & 0.16 & $(0.02,0.30)$ & 0.023 \\
\hline \multicolumn{7}{|l|}{ Number of previous pregnancies } \\
\hline 0 & Ref & & & Ref & & \\
\hline$\geq 1$ & -0.01 & $(-0.13,0.11)$ & 0.88 & 0.04 & $(-0.08,0.15)$ & 0.52 \\
\hline \multicolumn{7}{|l|}{ Empowerment } \\
\hline Self-reported empowerment level & 0 & $(-0.02,0.03)$ & 0.78 & 0.02 & $(-0.01,0.04)$ & 0.16 \\
\hline \multicolumn{7}{|l|}{ Food security } \\
\hline Asset score & 0.03 & $(-0.01,0.06)$ & 0.15 & -0.01 & $(-0.04,0.03)$ & 0.75 \\
\hline Household mean intakes per capita & 0.13 & $(0.04,0.22)$ & 0.007 & -0.02 & $(-0.10,0.07)$ & 0.70 \\
\hline \multicolumn{7}{|l|}{ Husband working overseas } \\
\hline Not working overseas & Ref & & & Ref & & \\
\hline Working overseas & -0.06 & $(-0.20,0.08)$ & 0.39 & 0.14 & $(0.01,0.27)$ & 0.035 \\
\hline \multicolumn{7}{|l|}{ Caste/religious group } \\
\hline Dalit or Muslim (disadvantaged) & Ref & & & Ref & & \\
\hline Janajati/other Terai castes & 0.05 & $(-0.08,0.17)$ & 0.49 & 0.08 & $(-0.04,0.20)$ & 0.19 \\
\hline $\begin{array}{l}\text { Yadav/Brahmin (least } \\
\text { disadvantaged) }\end{array}$ & -0.04 & $(-0.20,0.12)$ & 0.60 & -0.04 & $(-0.19,0.10)$ & 0.56 \\
\hline \multicolumn{7}{|l|}{ Season } \\
\hline Pre-monsoon & Ref & & & Ref & & \\
\hline Monsoon & -0.03 & $(-0.14,0.08)$ & 0.58 & -0.02 & $(-0.12,0.08)$ & 0.71 \\
\hline \multicolumn{7}{|l|}{$\log -M P A$ ratio } \\
\hline Crude mean outcome $(n=149)$ & -0.47 & $\begin{array}{l}(-0.72 \\
-0.22)\end{array}$ & $<0.001$ & -0.54 & $\begin{array}{l}(-0.76 \\
-0.31)\end{array}$ & $<0.001$ \\
\hline$n$ (fitted in multivariable model) & 144 & & & 145 & & \\
\hline \multicolumn{7}{|c|}{ Earning disparities between pregnant women and their spouse } \\
\hline Earns less than the spouse & Ref & & & Ref & & \\
\hline Earns more or same as the spouse & -0.05 & $(-0.80,0.70)$ & 0.90 & 0.14 & $(-0.18,0.46)$ & 0.39 \\
\hline \multicolumn{7}{|l|}{ Number of previous pregnancies } \\
\hline 0 & Ref & & & Ref & & \\
\hline$\geq 1$ & 0.29 & $(-0.32,0.90)$ & 0.35 & 0.08 & $(-0.19,0.34)$ & 0.56 \\
\hline \multicolumn{7}{|l|}{ Empowerment } \\
\hline Self-reported empowerment level & -0.03 & $(-0.15,0.08)$ & 0.57 & 0.00 & $(-0.05,0.05)$ & 0.89 \\
\hline \multicolumn{7}{|l|}{ Food security } \\
\hline Asset score & 0.03 & $(-0.14,0.21)$ & 0.71 & 0.02 & $(-0.05,0.10)$ & 0.55 \\
\hline Household mean intakes per capita & 0.07 & $(-0.39,0.52)$ & 0.78 & 0.43 & $(0.23,0.63)$ & $<0.001$ \\
\hline \multicolumn{7}{|l|}{ Husband working overseas } \\
\hline Not working overseas & Ref & & & Ref & & \\
\hline Working overseas & 0 & $(-0.69,0.68)$ & 0.99 & 0.22 & $(-0.07,0.52)$ & 0.14 \\
\hline \multicolumn{7}{|l|}{ Caste/religious group } \\
\hline Dalit or Muslim (disadvantaged) & Ref & & & Ref & & \\
\hline
\end{tabular}


Table 5 (continued)

\begin{tabular}{|c|c|c|c|c|c|c|}
\hline & \multicolumn{3}{|c|}{ Pregnant woman : household head } & \multicolumn{3}{|c|}{ Pregnant woman : mother-in-law } \\
\hline & Coeff. & $(95 \% \mathrm{CI})$ & $P$ & Coeff. & $(95 \% \mathrm{CI})$ & $P$ \\
\hline Janajati/other Terai castes & 0.33 & $(-0.31,0.97)$ & 0.32 & 0.2 & $(-0.08,0.48)$ & 0.16 \\
\hline $\begin{array}{l}\text { Yadav/Brahmin (least } \\
\text { disadvantaged) }\end{array}$ & 0.89 & $(0.11,1.67)$ & 0.026 & 0.25 & $(-0.09,0.59)$ & 0.14 \\
\hline \multicolumn{7}{|l|}{ Season } \\
\hline Pre-monsoon & Ref & & & Ref & & \\
\hline Monsoon & 0.18 & $(-0.37,0.72)$ & 0.53 & -0.06 & $(-0.30,0.17)$ & 0.60 \\
\hline
\end{tabular}

Variance inflation factors $\leq 1.5$

$73 \%$ of household heads who consumed at least some food outside of the home. However, we found no significant differences between self-reported and proxy-estimated calorie intakes, suggesting that any bias introduced by using a proxy respondent is likely to be minimal. Using standard rather than individual recipes might have falsely reduced variance in intakes, but are unlikely to have affected allocation estimates; whereas, it is possible that not applying retention factors biased the adequacy ratios, if certain household members consumed systematically more raw or cooked foods.

Our findings can be used to predict how interventions might influence intra-household food allocation. General increases in food security could increase nutritional equity, but programmes increasing availability of low-status foods (such as green leafy vegetables) could disproportionately benefit women, while increasing availability of animalsource foods may disproportionately benefit men. This hypothesis is supported by two Bangladeshi studies. One found that vegetables promoted in a gardening intervention, that were considered inferior, were selectively channelled to women [51]; another found that rice transfers (high status) were disproportionately consumed by men, whereas wheat transfers (low status) were channelled to women [52]. Furthermore, numerous kitchen garden interventions have improved women's consumption of fruits and vegetables [15], whereas livestock programmes have produced mixed effects on consumption of animal-source foods [15, 53]. Programmes targeting women could try to influence perceptions about the status of foods, and (preferably) also influence women's sociocultural status, although qualitative research is needed to understand how these changes in perceptions could be achieved. Beyond these gender dynamics, we can also predict how interventions might affect allocation to pregnant women specifically. Given that household-level calorie consumption was positively associated with higher equity for pregnant women, these abovementioned interventions may selectively benefit pregnant women simply by increasing household-level food availability. Other interventions to increase pregnant women's relative cash income, such as employment opportunities, higher wages or cash transfers, might also increase the allocation of foods to pregnant women. If so, a crucial next step would be to explore how these income-generating interventions can benefit women without adding to their work burdens, energy expenditure or compromising their ability to care for themselves and their children.

Acknowledgements We thank Rinku Tiwari, Neha Sharma and Kabita Sah for their help with recipe collection, and the respondents for participating in the study. We thank Mary Arimond for sharing technical inputs, and Maria Joseph-King, Alicia Carriquiry and Doris Wiesmann for the Stata syntax that informed our analyses. We are grateful for inputs from Nawaraj Upadhaya, Elaine Ferguson and Sarah Kehoe, who commented on earlier drafts. Sources of support: This work was supported by Child Health Research CIO; and UK Department for International Development (grant number PO 5675). Some work for this study was done at Great Ormond Street Hospital and the UCL Great Ormond Street Institute of Child Health, which received funding from the UK Department of Health's NIHR Biomedical Research Centres funding scheme. Partial funding of coauthors (NMS and AMdLC) was funded by Wellcome Trust Strategic Award for the Population Science of Maternal and Newborn Survival. Grant number: $085417 \mathrm{MA} / \mathrm{Z} / 08 / \mathrm{Z}$. No funders had any role in the design, analysis or writing of this article.

Author contributions HAH-F prepared the first draft of the manuscript, developed the overall study design and final tools and conducted analyses with input from MC-B and NMS. AMDLC provided technical oversight. BJB developed the concept of the smartphone components, and supported TH to develop the proof of concept for this. TH led the pilot testing and collection of utensil data with PP and HAH-F. NS collected weights of discrete food items. PP, HAH-F and NS trained data collectors and PP and SJ managed the data collection. HAH-F processed the data, and HAH-F, NS and PP routinely checked the outputs. DSM and BPS were responsible for day-to-day oversight and coordination of field activities. All authors read and approved the final manuscript.

\section{Compliance with ethical standards}

Conflict of interest The authors declare that they have no conflict of interest.

Ethical approval Research ethics approval was obtained from the Nepal Health Research Council (108/2012) and the UCL Ethical Review Committee (4198/001). All trial participants gave written 
consent at enrolment in the trial. Verbal informed consent was obtained from all subjects for subsequent interactions. Verbal consent was obtained and formally recorded on paper forms.

Open Access This article is licensed under a Creative Commons Attribution 4.0 International License, which permits use, sharing, adaptation, distribution and reproduction in any medium or format, as long as you give appropriate credit to the original author(s) and the source, provide a link to the Creative Commons license, and indicate if changes were made. The images or other third party material in this article are included in the article's Creative Commons license, unless indicated otherwise in a credit line to the material. If material is not included in the article's Creative Commons license and your intended use is not permitted by statutory regulation or exceeds the permitted use, you will need to obtain permission directly from the copyright holder. To view a copy of this license, visit http://creativecommons. org/licenses/by/4.0/.

\section{References}

1. Henjum S, Torheim LE, Thorne-Lyman AL, Chandyo R, Fawzi WW, Shrestha PS, et al. Low dietary diversity and micronutrient adequacy among lactating women in a peri-urban area of Nepal. Public Health Nutr. 2015;18:3201-10.

2. Arsenault JE, Yakes EA, Islam MM, Hossain MB, Ahmed T, Hotz C, et al. Very low adequacy of micronutrient intakes by young children and women in rural Bangladesh is primarily explained by low food intake and limited diversity. J Nutr. 2013;143:197-203.

3. Jiang T, Christian P, Khatry SK, Wu L, West KP. Micronutrient deficiencies in early pregnancy are common, concurrent, and vary by season among rural Nepali pregnant women. J Nutr. 2005; 135:1106-12.

4. Strauss RS, Dietz WH. Low maternal weight gain in the second or third trimester increases the risk for intrauterine growth retardation. J Nutr. 1999;129:988-93.

5. Akhtar S, Ismail T, Atukorala S, Arlappa N. Micronutrient deficiencies in South Asia-Current status and strategies. Trends Food Sci Technol. 2013;31:55-62.

6. Marphatia AA, Cole TJ, Grijalva-Eternod C, Wells JC. Associations of gender inequality with child malnutrition and mortality across 96 countries. Glob Health, Epidemiol Genom. 2016;1:e6.

7. Gittelsohn J, Thapa M, Landman LT. Cultural factors, caloric intake and micronutrient sufficiency in rural Nepali households. Soc Sci Med. 1997;44:1739-49.

8. Sudo N, Sekiyama M, Maharjan M, Ohtsuka R. Gender differences in dietary intake among adults of Hindu communities in lowland Nepal: assessment of portion sizes and food consumption frequencies. Eur J Clin Nutr. 2006;60:469-77.

9. Berti PR. Intrahousehold distribution of food: a review of the literature and discussion of the implications for food fortification programs. Food Nutr Bull. 2012;33:S163-S170.

10. Behrman JR, Deolalikar AB. The intrahousehold demand for nutrients in rural south India: individual estimates, fixed effects, and permanent income. J Hum Resour. 1990;25:665-96.

11. Gittelsohn J. Opening the box: intrahousehold food allocation in rural Nepal. Soc Sci Med. 1991;33:1141-54.

12. Khan M, Anker R, Ghosh Dastidar S, Bairathi S. Inequalities between men and women in nutrition and family welfare services: an in-depth enquiry in an Indian village. In: Population and Labour Policies Programme, Working Paper No. 158, UNFPA Project No. INT/83/P34. Geneva: World Employment Programme Research; 1987.
13. Morrison J, Dulal S, Harris-Fry H, Basnet M, Sharma N, Shrestha $B$ et al. Formative qualitative research to develop communitybased interventions addressing low birth weight in the plains of Nepal. Public Health Nutr. 2017:1-8. https://doi.org/10.1017/ S1368980017002646.

14. Bhutta ZA, Das JK, Rizvi A, Gaffey MF, Walker N, Horton S, et al. Evidence-based interventions for improvement of maternal and child nutrition: what can be done and at what cost? Lancet. 2013;382:452-77.

15. Girard AW, Self JL, McAuliffe C, Olude O. The effects of household food production strategies on the health and nutrition outcomes of women and young children: a systematic review. Paediatr Perinat Epidemiol. 2012;26:205-22.

16. Harris-Fry H, Shrestha N, Costello A, Saville NM. Determinants of intra-household food allocation between adults in South Asia a systematic review. Int J Equity Health. 2017;16:107. https://doi. org/10.1186/s12939-017-0603-1

17. Central Bureau of Statistics. National population and housing census 2011, National Report. Kathmandu, Nepal: Central Bureau of Statistics, Government of Nepal; 2012.

18. Ministry of Health N, New ERA, ICF. Nepal demographic and health survey 2016. Kathmandu: Ministry of Health N; 2017.

19. Saville NM, Shrestha BP, Style S, Harris-Fry H, Beard BJ, Sengupta A, et al. Protocol of the Low Birth Weight South Asia Trial (LBWSAT), a cluster-randomised controlled trial testing impact on birth weight and infant nutrition of participatory learning and action through women's groups, with and without unconditional transfers of fortified food or cash during pregnancy in Nepal. BMC Pregnancy Childbirth. 2016;16:320.

20. Style S, Beard BJ, Harris-Fry HA, Sengupta A, Jha S, Shrestha B, et al. Experiences in running a complex electronic data capture system using mobile phones in a large-scale population trial in southern Nepal. Glob Health Action. 2017;10:1330858 https://doi. org/10.1080/16549716.2017.1330858

21. Harris-Fry HA, Beard BJ, Harrisson T, Paudel P, Shrestha N, Jha $\mathrm{S}$, et al. Smartphone tool to collect repeated 24-hour dietary recall data in Nepal. Public Health Nutr. 2017. https://doi.org/10.1017/ S136898001700204X

22. Moshfegh AJ, Rhodes DG, Baer DJ, Murayi T, Clemens JC, Rumpler WV, et al. The US Department of Agriculture Automated Multiple-Pass Method reduces bias in the collection of energy intakes. Am J Clin Nutr. 2008;88:324-32.

23. Gibson RS, Ferguson EL. An interactive 24-hour recall for assessing the adequacy of iron and zinc intakes in developing countries. Washington DC: International Life Sciences Institute; 1999.

24. Harris-Fry H, Paudel P, Karn M, Mishra N, Thakur J, Paudel V, et al. Development and validation of a photographic food atlas for portion size assessment in the southern plains of Nepal. Public Health Nutr. 2016;19:2495-507.

25. Shaheen N, Rahim T, Mohiduzzaman M, Banu C, Bari ML, Tukun A et al. Food composition table for Bangladesh. Institute of Nutrition and Food Science, Centre for Advanced Research in Sciences. Dhaka, Bangladesh: University of Dhaka; 2013.

26. U.S. Department of Agriculture ARS. USDA nutrient database for standard reference, release 25. In: Nutrient DataLaboratory Home Page. USDA. 2012. https://www.ars.usda.gov/northeast-area/ beltsville-md/beltsville-human-nutrition-research-center/nutrientdata-laboratory/docs/sr25-home-page/. Accessed August 2017.

27. Finglas P, Roe M, Pinchen H, Berry R, Church S, Dodhia S et al. McCance and Widdowson's the composition of foods integrated dataset 2015. London: Public Health England; 2015.

28. Ministry of Agriculture Development. Food composition table for Nepal. Department of Food Technology and Quality Control. Kathmandu, Nepal: Food and Agriculture Organization; 2012. 
29. Bilinsky P, Swindale A. Months of Adequate Household Food Provisioning (MAHFP) for measurement of household food access: indicator guide (v.4). Washington, DC: FHI 360/FANTA; 2010.

30. Coates J, Swindale A, Bilinsky P (2007) Food and Nutrition Technical Assistance Project (FANTA): Household Food Insecurity Access Scale (HFIAS) for measurement of food access: indicator guide (v. 3). Washington, DC: Food and Nutrition Technical Assistance Project.

31. FAO, FHI 360. Minimum dietary diversity for women: a guide to measurement. Rome: FAO; 2016.

32. Carriquiry AL. Assessing the prevalence of nutrient inadequacy. Public Health Nutr. 1999;2:23-34.

33. National Research Council. The probability approach. Washington, DC: National Academies Press; 1986.

34. Box GE, Cox DR. An analysis of transformations. J R Stat Soc Series B Stat Methodol. 1964;26:211-52.

35. FAO/WHO. Human vitamin and mineral requirements: report of a joint FAO/WHO expert consultation. Bangkok, Thailand, and Rome, Italy: Food and Agriculture Organization of the United Nations, and World Health Organization; 2001.

36. Food and Nutrition Board, Committee to Review Dietary Reference Intakes for Vitamin D and Calcium. Dietary reference intakes for calcium and vitamin D. Washington, DC: The National Academies Press; 2011.

37. Food and Nutrition Board, Institute of Medicine. Dietary reference intakes for vitamin $\mathrm{A}$, vitamin $\mathrm{K}$, arsenic, boron, chromium, copper, iodine, iron, manganese, molybdenum, nickel, silicon, vanadium, and Zinc. In: A Report of the Panel on Micronutrients, Subcommittees on Upper Reference Levels of Nutrients and of Interpretation and Uses of Dietary Reference Intakes, and the Standing Committee on the Scientific Evaluation of Dietary Reference Intakes. National Academy Press: Washington, DC; 2001.

38. Hotz C, Brown KH. Assessment of the risk of zinc deficiency in populations and options for its control. Food Nutr Bull. 2004;25:194-5.

39. Bouis HE, Novenario-Reese MJG. The determinants of demand for micronutrients, FCND Discussion Paper No. 32. Washington, DC: International Food Policy Research Institute (IFPRI); 1997.

40. ICMR. Nutrient requirements and recommended dietary allowances for Indians. Hyderabad, India: National Institute of Nutrition, Indian Council of Medical Research; 2010.

41. Stine RA. Graphical interpretation of variance inflation factors. Am Stat. 1995;49:53-56.
42. Tang AM, Dong K, Deitchler M, Chung M, Maalouf-Manasseh Z, Tumilowicz A et al. Use of cutoffs for Mid-Upper Arm Circumference (MUAC) as an indicator or predictor of nutritional and health-related outcomes in adolescents and adults: a systematic review. Washington, DC, USA: Food and Nutrition Technical Assistance III Project (FANTA); 2013.

43. Sudo N, Sekiyama M, Ohtsuka R, Maharjan M. Gender differences in 'Luxury Food Intake' owing to temporal distribution of eating occasions among adults of hindu communities in Lowland Nepal. Asia Pac J Clin Nutr. 2009;18:441.

44. Kondos V. On the ethos of hindu women: issues, taboos, and forms of expression. Kathmandu, Nepal: Mandala Publications; 2004.

45. Harding KL, Matias SL, Mridha MK, Vosti SA, Hussain S, Dewey KG et al. Eating down or simply eating less? The diet and health implications of these practices during pregnancy and postpartum in rural Bangladesh. Public Health Nutr. 2017;20:1928-40.

46. Nelson M, Haraldsdóttir J. Food photographs: practical guidelines I. Design and analysis of studies to validate portion size estimates. Public Health Nutr. 1998;1:219-30.

47. Bingham SA. Limitations of the various methods for collecting dietary intake data. Ann Nutr Metab. 1991;35:117-27.

48. Appadurai A. Gastropolitics in Hindu South Asia. Am Ethnol. 1981;8:494-511.

49. Pitt MM, Rosenzweig MR, Hassan MNH. Productivity, health and inequality in the intrahousehold distribution of food in lowincome countries. Am Econ Rev. 1990;80:1139-56.

50. Clarke K, Saville N, Bhandari B, Giri K, Ghising M, Jha M, et al. Understanding psychological distress among mothers in rural Nepal: a qualitative grounded theory exploration. BMC Psychiatry. 2014;14:1-13.

51. Naved RT. Intrahousehold impact of the transfer of modern agricultural technology: a gender perspective. Washington, DC, USA: International Food Policy Research Institute (IFPRI); 2000.

52. Ahmed AU, Quisumbing AR, Hoddinott JF, Nasreen M, Bryan E (2007) Relative efficacy of food and cash transfers in improving food security and livelihoods of the ultra-poor in Bangladesh. Washington, DC: International Food Policy Research Institute (IFPRI).

53. Jones KM, Specio SE, Shrestha P, Brown KH, Allen LH. Nutrition knowledge and practices, and consumption of vitamin $\mathrm{A}-$ rich plants by rural Nepali participants and nonparticipants in a kitchen-garden program. Food Nutr Bull. 2005;26:198-208. 